\title{
Desenvolvimento e nodulação natural de leguminosas arbóreas em solos de Pernambuco
}

\author{
Luiz Augusto Gomes de Souza(1), Egídio Bezerra Neto(2), Carolina Etienne de Rosália Silva Santos ${ }^{(2)}$ \\ e Newton Pereira Stamford(2)
}

\begin{abstract}
(1)Instituto Nacional de Pesquisas da Amazônia, Coordenação de Pesquisas em Ciências Agronômicas, Av. André Araújo, 2936, Petrópolis, CEP 69083-000 Manaus, AM. E-mail: souzalag@inpa.gov.br (2)Universidade Federal Rural de Pernambuco, Dep. de Biologia, Rua Dom Manuel de Medeiros, s/no, Dois Irmãos, CEP 52171-900 Recife, PE. E-mail: egidio@ufrpe.br, etienne@ufrpe.br, npstamford@ufrpe.br
\end{abstract}

Resumo - O objetivo deste trabalho foi avaliar o desenvolvimento e nodulação natural de leucena (Leucaena leucocephala), palheteira (Clitoria fairchildiana) e sabiá (Mimosa caesalpiniifolia), em solos com diferentes formas de uso da terra, da Zona da Mata de Pernambuco. Foram utilizados quatro solos de mata, seis solos de áreas agrícolas e dois de áreas degradadas. Os solos foram classificados, analisados quimicamente e distribuídos, $3 \mathrm{~kg}$ de solo por vaso, com duas plantas por vaso. A colheita das mudas foi feita aos 76, 70 e 62 dias, para leucena, palheteira e sabiá, respectivamente. O delineamento experimental foi inteiramente casualizado, com 12 tratamentos e 3 repetições. Foram constatadas baixas frequiências de populações nativas de rizóbios para leucena, $22 \%$ de plantas noduladas, em comparação à palheteira e sabiá, 100 e $86 \%$, respectivamente. A palheteira apresentou nodulação natural abundante e eficiência na fixação de $\mathrm{N}_{2}$, o que demonstra compatibilidade com as populações nativas de rizóbios. O crescimento, o desenvolvimento, a nodulação e o acúmulo de nitrogênio das três espécies foram favorecidos no solo de área agrícola com cobertura de Calopogonium mucunoides. A palheteira apresentou o maior potencial para fixação de $\mathrm{N}_{2}$ e eficiência da nodulação com populações nativas de rizóbios, seguida por sabiá e leucena.

Termos para indexação: Clitoria fairchildiana, Leucaena leucocephala, Mimosa caesalpiniifolia, fixação biológica de $\mathrm{N}_{2}$, ecologia, rizóbio, biologia do solo.

\section{Development and natural nodulation of legume trees in soils from Pernambuco, Brazil}

\begin{abstract}
The objective of this work was to evaluate the development and natural nodulation of Leucaena leucocephala, Clitoria fairchildiana and Mimosa caesalpiniifolia, in soils with different type of land use, in Zona da Mata of Pernambuco, Brazil. Soils of four forest areas, six agriculture areas and two degraded areas were used. Soils were classified, analyzed chemically and distributed in pots $3 \mathrm{~kg}$ soil per pot, two plants per pot. Plant evaluations were carried out at 76,70 and 62 days, for L. leucocephala, C. fairchildiana and M. caesalpiniifolia, respectively. The experimental design was completely randomized, with 12 treatments and 3 repetitions. Low frequencies of native populations of rhizobia were verified for $L$. leucocephala, with $22 \%$ of plants nodulated, compared to C. fairchildiana and M. caesalpiniifolia, with $100 \%$ and $86 \%$, respectively. M. caesalpiniifolia presented abundant natural nodulation and efficiency in the fixation of $\mathrm{N}_{2}$, demonstrating compatibility with native populations of rhizobia. Growth, development, nodulation as well as accumulation of nitrogen of the three species, were favored with soil under agricultural areas with covering of Calopogonium mucunoides. C. fairchildiana presented greater potential for fixation of $\mathrm{N}_{2}$ and efficiency of the nodulation with native populations of rhizobia followed by M. caesalpiniifolia and L. leucocephala.
\end{abstract}

Index terms: Clitoria fairchildiana, Leucaena leucocephala, Mimosa caesalpiniifolia, biological $\mathrm{N}_{2}$ fixation, ecology, rhizobia, soil biology.

\section{Introdução}

A associação ente bactérias e leguminosas reflete parâmetros evolutivos entre os hospedeiros, pelo reconhecimento de sinais moleculares e especificidade simbiótica. Leguminosas primitivas eram árvores da região tropical e muitas espécies evoluíram e diversificaram-se em várias partes do mundo. Hoje, espécies introduzidas se desenvolvem bem longe de seus centros de origem. Uma leguminosa introduzida formará 
nódulos e se beneficiará da fixação biológica de $\mathrm{N}_{2}$ (FBN), em dado local, se populações nativas de rizóbios compatíveis estiverem presentes no solo. A eficiência do processo depende, porém, de fatores da planta, da bactéria, do clima e do solo.

O estímulo ao plantio de leguminosas arbóreas, como alternativa para recuperar solos e para reflorestamento, deve ser precedido por pesquisa que avalie o potencial de nodulação das espécies em condições locais e conseqüente prospecção de microrganismos do solo com potencial para uso como inoculante.

Ao se cultivar leguminosas introduzidas, a espécie pode associar-se com rizóbio nativo ou com estirpes de rizóbio introduzidas no solo por meio de inoculação nas sementes (Bala et al., 2003). A diversidade genética de árvores fixadoras de nitrogênio, bem como sua capacidade de nodulação, é um fator a ser considerado na recuperação de solos em sistemas de produção sustentáveis. Algumas estimativas sobre a contribuição da FBN para leguminosas arbóreas foram efetuadas, e entre gêneros de maior potencial estão Acacia, Albizia, Calliandra, Gliricidia, Inga, Leucaena e Prosopis (Fortes et al., 2004).

Quanto aos rizóbios, após extensivas análises de características fenotípicas, genotípicas e moleculares, os isolados obtidos de leguminosas arbóreas nativas estão classificados dentro dos seguintes gêneros: Rhizobium, Bradyrhizobium, Sinorhizobium e Mesorhizobium (Zahran, 2001). No entanto, à medida que novos estudos surgem são propostas reclassificações das estirpes, com novos gêneros, como Burkholderia (Vandame et al., 2002) Azorhizobium e Methylobacterium (Menna et al., 2006).

A área litorânea de Pernambuco, conhecida como Zona da Mata, era originalmente recoberta por Mata Atlântica, e, junto com áreas dos Estados de Alagoas, Paraíba e Rio Grande do Norte compõem um centro de endemismo que tem sido intensivamente destruído. Em seu histórico da ocupação, práticas agrícolas seculares, extração de madeira, queimadas, estabelecimento de pastos e canaviais e a expansão urbana, alteraram e reduziram a floresta original (Barbosa \& Thomas, 2002). Em muitas áreas, o final do processo de desmatamento foi a erosão e degradação do solo com dominância de gramíneas e outras invasoras. Atualmente, a Floresta Atlântica, que originalmente recobria $16 \%$ do território pernambucano, encontra-se bastante reduzida e dispersa em fragmentos de diferentes tamanhos. Comparado a outras áreas da
Floresta Atlântica no Brasil, o centro de endemismo de Pernambuco é o mais desmatado, o mais desconhecido e o menos protegido (Araújo \& Tabarelli, 2002). Resta menos de 5\% da vegetação original (Vianna et al., 1997), com muitas áreas improdutivas que necessitam de práticas de recuperação da cobertura vegetal.

Práticas de reflorestamento e recuperação de solos com leguminosas arbóreas se constituem em opção na recuperação de áreas degradadas e no estabelecimento de corredores ecológicos no litoral de Pernambuco. Muitas dessas árvores têm rápido crescimento, múltiplo uso, são de fácil propagação, apresentam potencial para incremento genético e significância ecológica pela FBN (Franco \& Faria, 1997).

A prospecção de nodulação natural de espécies arbóreas, em solos locais, associada a um programa de prospecção de novas estirpes, com posterior aplicação de testes de eficiência agronômica com estirpes potenciais e estirpes recomendadas, são importantes para a definição de quais espécies podem ser plantadas para a recuperação de áreas alteradas. Assim, em razão das diferenças na habilidade nodulífera de leguminosas arbóreas com estirpes nativas, a bioprospecção de rizóbios em solos locais pode fornecer subsídios sobre a eficiência da nodulação natural e fixação de nitrogênio das espécies.

O objetivo deste trabalho foi avaliar o desenvolvimento e a nodulação natural de mudas de leucena (Leucaena leucocephala), palheteira (Clitoria fairchildiana) e sabiá (Mimosa caesalpiniifolia), em solos da Zona da Mata de Pernambuco com diferentes formas de uso da terra: mata, áreas agrícolas e áreas degradadas.

\section{Material e Métodos}

Foram coletadas 12 amostras de solos $(0-20 \mathrm{~cm})$ em municípios do litoral de Pernambuco, entre julho e agosto de 2003; considerou um gradiente de coberturas para caracterizar as alterações da paisagem: quatro amostras de solos de mata, seis amostras de solos de áreas agrícolas e duas amostras de solos de áreas degradadas (Tabela 1). As amostras foram secadas ao ar, passadas em peneira com malhas de $2 \mathrm{~cm}$ e distribuídas na proporção de $3 \mathrm{~kg}$ por vaso.

Os solos foram classificados de acordo com Lemos \& Santos (1996), Burgos et al. (1998) e Embrapa (1999) (Tabela 2). Foram determinadas as propriedades físicas e químicas dos solos (Tabelas 2, 3 e 4). A análise textural (método da pipeta) e a da matéria orgânica foram 
realizadas no Centro de Pesquisas de Solos do Departamento de Agronomia da UFRPE, em Recife, PE, segundo métodos descritos em Embrapa (1997). As demais análises foram realizadas no Laboratório de Fertilidade do Solo, da Empresa Pernambucana de Pesquisa Agropecuária, em Recife. $\mathrm{O}$ pH foi determinado em água (1:2,5); o $\mathrm{Ca}, \mathrm{Mg}$ e $\mathrm{Al}$ foram extraídos com $\mathrm{KCl} 1 \mathrm{~N}$; o $\mathrm{K}$ e o $\mathrm{Na}$ foram determinados por fotometria de chama; o $\mathrm{P}$ foi extraído com o extrator Mehlich 1 e determinado por espectrofotometria.

A fim de determinar a presença de rizóbios que podem nodular leguminosas arbóreas, nas amostras de solo,

Tabela 1. Localização e descrição das formas de uso da terra nas áreas de estudo da Zona da Mata de Pernambuco.

\begin{tabular}{|c|c|c|}
\hline Área/município & $\begin{array}{l}\text { Coordenadas } \\
\text { geográficas }\end{array}$ & Descrição sucinta da área amostrada \\
\hline \multicolumn{3}{|r|}{ Área de mata } \\
\hline 1. Cabo de Santo & $08^{\circ} 18^{\prime} 37,6^{\prime \prime} \mathrm{S}$ & Imediações da Mata do Zumbi. Árvores com $8 \mathrm{~m}$ de altura, em um sítio \\
\hline Agostinho & $34^{\circ} 51^{\prime} 89,9^{\prime \prime} \mathrm{W}$ & abandonado, dentro do contínuo de mata. \\
\hline 2. Camaragibe & $08^{\circ} 01^{\prime} 22,2^{\prime \prime} \mathrm{S}$ & Mata do Prive. Sob a copa de uma árvore não leguminosa, de $12 \mathrm{~m}$ de altura. \\
\hline 3. Recife & $\begin{array}{l}34^{\circ} 59^{\prime} 19,0^{\prime \prime} \mathrm{W} \\
08^{\circ} 01^{\prime} 00,1^{\prime \prime} \mathrm{S} \\
34^{\circ} 56^{\prime} 67,8^{\prime \prime} \mathrm{W}\end{array}$ & $\begin{array}{l}\text { Solo com presença de minhocas. } \\
\text { Parque Ecológico Dois Irmãos. Árvores com } 10 \mathrm{~m} \text { de al tura. Presença de cipós e } \\
\text { espessa camada de liteira. }\end{array}$ \\
\hline 4. São Lourenço da Mata & $\begin{array}{l}08^{\circ} 47^{\prime} 21,4^{\prime \prime} \mathrm{S} \\
34^{\circ} 03^{\prime} 28,4^{\prime \prime} \mathrm{W}\end{array}$ & $\begin{array}{l}\text { Mata secundária próxima à BR } 408 \text {. Trecho com plantas lenhosas pioneiras, em } \\
\text { fase ativa da sucessão vegetal. }\end{array}$ \\
\hline \multicolumn{3}{|r|}{ Área de agricultura } \\
\hline 1. Camaragibe & $\begin{array}{l}07^{\circ} 56^{\prime} 74,3^{\prime \prime} \mathrm{S} \\
35^{\circ} 01^{\prime} 43,8^{\prime \prime} \mathrm{W}\end{array}$ & $\begin{array}{l}\text { Estrada de Aldeia, PE 27, } \mathrm{Km} \text { 18. Área plantada com milho e mandioca, } \\
\text { intercalada por árvores de acerola. }\end{array}$ \\
\hline 2. Chã de Alegria & $\begin{array}{l}08^{\circ} 53^{\prime} 04,2^{\prime \prime} \mathrm{S} \\
35^{\circ} 37^{\prime} 35,4^{\prime \prime} \mathrm{W}\end{array}$ & $\begin{array}{l}\text { Área cultivada com mandioca e fava ( Vicia } f a b a \text { ), sem capina, com presença de } \\
\text { plantas invasoras. }\end{array}$ \\
\hline 3. Carpina & $\begin{array}{l}07^{\circ} 51^{\prime} 20,2^{\prime \prime} \mathrm{S} \\
35^{\circ} 14^{\prime} 16,8^{\prime \prime} \mathrm{W}\end{array}$ & $\begin{array}{l}\text { Plantio da leguminosa feijão-macassar (Vigna unguiculata). As plantas } \\
\text { encontravam-se em fase de produção e colheita. }\end{array}$ \\
\hline 4. Paudalho & $\begin{array}{l}07^{\circ} 52^{\prime} 25,2^{\prime \prime} \mathrm{S} \\
35^{\circ} 32^{\prime} 18,9^{\prime \prime} \mathrm{W}\end{array}$ & $\begin{array}{l}\text { Estrada vicinal da BR 404, com cobertura densa da leguminosa calopogônio } \\
\text { (Calopogonium mucunoides). }\end{array}$ \\
\hline $\begin{array}{l}\text { 5. Cabo de Santo } \\
\text { Agostinho }\end{array}$ & $\begin{array}{l}08^{\circ} 18^{\prime} 95,0^{\prime \prime} \mathrm{S} \\
35^{\circ} 00^{\prime} 84,2^{\prime \prime} \mathrm{W}\end{array}$ & Monocultivo de cana-de-açúcar, sem a presença de plantas invasoras. \\
\hline 6. Carpina & $\begin{array}{l}07^{\circ} 53^{\prime} 21,8^{\prime \prime} \mathrm{S} \\
35^{\circ} 16^{\prime} 85,7^{\prime \prime} \mathrm{W} \\
\end{array}$ & Área experimental da UFRPE, cultivada há mais de 5 anos com cana-de-açúcar. \\
\hline 1. Camaragibe & $\begin{array}{l}08^{\circ} 01^{\prime} 62,7^{\prime \prime} \mathrm{S} \\
34^{\circ} 59^{\prime} 23,4^{\prime \prime} \mathrm{W}\end{array}$ & $\begin{array}{l}\text { Área degradada } \\
\text { Encosta no morro Santo Antônio, em área colonizada por invasoras, } \\
\text { principalmente Brachiaria sp. e leguminosas herbáceas ocasionais como } \\
\text { Desmodium sp. }\end{array}$ \\
\hline 2. Paulista & $\begin{array}{l}07^{\circ} 58^{\prime} 73,0^{\prime \prime} \mathrm{S} \\
34^{\circ} 55^{\prime} 73,1^{\prime \prime} \mathrm{W}\end{array}$ & $\begin{array}{l}\text { Área de baixada, adjacente à BR 101. Solo exposto pela erosão intensa, com } \\
\text { presença de gramíneas e também leguminosas herbáceas dos gêneros Mimosa e } \\
\text { Zornia. }\end{array}$ \\
\hline
\end{tabular}

Tabela 2. Classificação, análise granulométrica e textura de solos coletados em áreas com diferentes formas de uso da terra, na Zona da Mata de Pernambuco.

\begin{tabular}{llcccl}
\hline \multirow{2}{*}{ Cobertura do solo } & \multicolumn{1}{c}{ Classes de solo } & \multicolumn{2}{c}{ Análise granulométrica $\left(\mathrm{g} \mathrm{kg}^{-1}\right)$} & \multirow{2}{*}{ Classificação textural } \\
\cline { 2 - 4 } & & Areia & Silte & Argila & \\
\hline Mata 1 & Argissolo Vermelho -Amarelo & 785 & 56 & 159 & Franco-arenoso \\
Mata 2 & Argissolo Vermelho -Amarelo & 635 & 166 & 199 & Franco-arenoso \\
Mata 3 & Espodossolo & 841 & 45 & 114 & Areia franca \\
Mata 4 & Latossolo Vermelho-Amarelo & 392 & 298 & 310 & Franco-argiloso \\
Agricultura 1 & Argissolo Vermelho -Amarelo & 705 & 71 & 224 & Franco-argilo-arenoso \\
Agricultura 2 & Latossolo Amarelo & 458 & 184 & 358 & Franco-argiloso \\
Agricultura 3 & Argissolo Vermelho-Amarelo & 765 & 61 & 174 & Franco-arenoso \\
Agricultura 4 & Latossolo Vermelho-Amarelo & 386 & 306 & 308 & Franco-argiloso \\
Agricultura 5 & Latossolo Vermelho-Escuro & 158 & 174 & 668 & Muito argiloso \\
Agricultura 6 & Argissolo Vermelho-Amarelo & 765 & 71 & 164 & Franco-arenoso \\
Degradada 1 & Latossolo Vermelho-Amarelo & 595 & 66 & 339 & Franco-argilo-arenoso \\
Degradada 2 & Alissolo Amarelo & 522 & 140 & 338 & Franco-argilo-arenoso \\
\hline
\end{tabular}


foram conduzidos três experimentos em casa de vegetação, de agosto a dezembro de 2003. As leguminosas estudadas foram leucena (Leucaena leucocephala (Lam.) De Wit. Mimosoideae, Eumimoseae), palheteira (Clitoria fairchildiana Howard Papilionoideae, Phaseoleae) e sabiá (Mimosa caesalpiniifolia Benth. Mimosoideae, Eumimoseae). Cada espécie constituiu um experimento.

As sementes de leucena foram procedentes de Manaus, AM, as de palheteira, de Recife, PE e as de sabiá, de Piracicaba, SP. As sementes de sabiá e leucena foram submetidas a choque térmico, com água em ebulição, seguido da imersão em água à temperatura ambiente por 24 horas, antes da semeadura em areia lavada e autoclavada. Foi utilizado pó de coco como cobertura de semeio. A semeadura foi a $1 \mathrm{~cm}$ de profundidade em linhas com parcelas de 50 sementes.
Aos 15 dias após a semeadura, foi feita a transferência de duas plântulas de cada espécie para os vasos. Durante os experimentos, o comprimento do caule e o diâmetro do colo das mudas foi medido regularmente, com régua e um paquímetro digital. Quanto a leucena, as medições foram aos 6, 28, 46 e 76 dias, após o transplantio. Em palheteira, aos 9, 29, 49 e 70 dias, e em sabiá, aos $11,29,52$ e 62 dias.

Na condução do ensaio, foi efetuada irrigação diária dos vasos a cerca de $80 \%$ de capacidade de campo com remoção regular de plantas invasoras. A colheita foi realizada aos 76, 70 e 62 dias, para leucena, palheteira e sabiá, respectivamente. Foram determinados o número de nódulos e a biomassa da parte aérea das raízes e dos nódulos, após a secagem em estufa a $65^{\circ} \mathrm{C}$ por 72 horas. Determinações da concentração de $\mathrm{N}$ foliar foram realizadas no Laboratório de Nutrição Mineral de Plantas

Tabela 3. Potencial hidrogeniônico, grau de acidez, teores de fósforo e de bases trocáveis em classes de solos coletados em áreas com diferentes formas de uso da terra, na Zona da Mata de Pernambuco.

\begin{tabular}{|c|c|c|c|c|c|c|c|}
\hline Cobertura do solo & $\mathrm{pH}\left(\mathrm{H}_{2} \mathrm{O}\right)$ & Acidez & $\begin{array}{c}\mathrm{P} \\
\left(\mathrm{mg} \mathrm{dm}^{-3}\right)\end{array}$ & $\mathrm{Ca}$ & $\mathrm{Mg}$ & $\begin{array}{r}K \\
\left.m^{-3}\right)\end{array}$ & $\mathrm{Na}$ \\
\hline Mata 1 & 5,24 & Moderada & 2 & 1,15 & 0,90 & 0,06 & 0,05 \\
\hline Mata 2 & 4,86 & Elevada & 3 & 1,10 & 1,40 & 0,17 & 0,05 \\
\hline Mata 3 & 4,38 & Elevada & 5 & 0,60 & 0,90 & 0,12 & 0,11 \\
\hline Mata 4 & 5,49 & Moderada & 10 & 2,25 & 1,90 & 0,44 & 0,15 \\
\hline Agricultura 1 & 5,33 & Moderada & 9 & 1,15 & 0,50 & 0,13 & 0,04 \\
\hline Agricultura 2 & 4,40 & Elevada & 3 & 0,35 & 0,50 & 0,12 & 0,10 \\
\hline Agricultura 3 & 5,90 & Fraca & 14 & 2,30 & 1,60 & 0,09 & 0,06 \\
\hline Agricultura 4 & 5,28 & Moderada & 20 & 2,50 & 2,70 & 0,19 & 0,08 \\
\hline Agricultura 5 & 4,70 & Elevada & 3 & 1,60 & 1,85 & 0,34 & 0,05 \\
\hline Agricultura 6 & 5,92 & Fraca & 26 & 2,40 & 1,75 & 0,30 & 0,07 \\
\hline Degradada 1 & 5,35 & Moderada & 2 & 1,25 & 0,75 & 0,07 & 0,04 \\
\hline Degradada 2 & 4,76 & Elevada & 1 & 0,10 & 0,25 & 0,03 & 0,03 \\
\hline
\end{tabular}

Tabela 4. Características químicas do solo, capacidade de troca de cátions e outras propriedades químicas de solos coletados em áreas com diferentes formas de uso da terra, da Zona da Mata de Pernambuco ${ }^{(1)}$.

\begin{tabular}{|c|c|c|c|c|c|c|c|c|}
\hline Cobertura do solo & $\begin{array}{c}\mathrm{MO} \\
\left(\mathrm{g} \mathrm{kg}^{-1}\right)\end{array}$ & $\mathrm{Al}^{3+}$ & $\begin{array}{l}\mathrm{H}+\mathrm{Al} \\
-\end{array}$ & $\begin{array}{c}\mathrm{S} \\
\left.\mathrm{m}^{-3}\right)\end{array}$ & CTC & V & $\mathrm{m}$ & $\begin{array}{c}\mathrm{NC} \\
\left(\mathrm{t} \mathrm{ha}^{-1}\right)\end{array}$ \\
\hline$\overline{\text { Mata } 1}$ & 5,7 & 0,15 & 4,53 & 2,2 & 6,7 & 32 (D) & 6 & 0,5 \\
\hline Mata 2 & 19,2 & 0,50 & 7,26 & 2,7 & 10,0 & 27 (D) & 16 & 1,0 \\
\hline Mata 3 & 7,9 & 1,60 & 12,62 & 1,7 & 14,4 & 12 (D) & 48 & 3.0 \\
\hline Mata 4 & 8,7 & 0,20 & 2,72 & 4,7 & 7,5 & $64(\mathrm{E})$ & 4 & 0,5 \\
\hline Agricultura 1 & 3,9 & 0,40 & 5,93 & 1,8 & 7,8 & 23 (D) & 18 & 1,0 \\
\hline Agricultura 2 & 18,2 & 1,50 & 6,10 & 1,1 & 7,2 & 15 (D) & 58 & 3,0 \\
\hline Agricultura 3 & 4,9 & 0,00 & 4,37 & 4,1 & 8,4 & 48 (D) & 0 & 0,0 \\
\hline Agricultura 4 & 22,8 & 0,15 & 6,43 & 5,5 & 11,9 & 46 (D) & 3 & 0,5 \\
\hline Agricultura 5 & 21,6 & 1,05 & 9,48 & 3,8 & 13,3 & 29 (D) & 21 & 2,0 \\
\hline Agricultura 6 & 7,3 & 0,05 & 3,95 & 4,5 & 8,5 & $53(\mathrm{E})$ & 1 & 0,0 \\
\hline Degradada 1 & 17,0 & 0,35 & 6,76 & 2,1 & 8,9 & 24 (D) & 14 & 0,5 \\
\hline Degradada 2 & 2,6 & 0,90 & 1,56 & 0,4 & 2,0 & 21 (D) & 69 & 4,0 \\
\hline
\end{tabular}

(1)MO: matéria orgânica; H+Al: acidez potencial; S: soma de bases; CTC: capacidade de troca de cátions; V: saturação de bases; m: saturação de alumínio; NC: necessidade de calagem; D: distrófico; E: eutrófico. 
da UFRPE, pelo método de Kjeldahl, empregando-se digestão sulfúrica (Bezerra Neto \& Barreto, 2004). Os valores da biomassa da parte aérea das plantas foram usados no cálculo do $\mathrm{N}$ total acumulado na parte aérea.

A fim de preservar as condições originais dos solos, não foi realizada correção com fertilizantes. Cada solo correspondeu a um tratamento. O delineamento experimental adotado foi o inteiramente casualizado, com 12 tratamentos (solos) e 3 repetições, empregando-se o teste de Tukey na comparação das médias.

Dados em porcentagem foram transformados para arc sen $(x+0,01)^{0,5}$ e dados de contagem do número de nódulos e da biomassa seca dos nódulos foram transformados para $(x+0,01)^{0,5}$. Foi realizada regressão linear da biomassa seca dos nódulos e $\mathrm{N}$ total acumulado na parte aérea para estimar a eficiência da simbiose estabelecida pelas leguminosas arbóreas e os rizóbios nativos dos solos.

\section{Resultados e Discussão}

Durante o período experimental, as mudas de leucena, palheteira e sabiá se desenvolveram normalmente e apresentaram índice de sobrevivência de $100 \%$. $\mathrm{O}$ crescimento em comprimento do caule das três espécies foi favorecido em solo com cobertura da leguminosa calopogônio, designado como Agricultura 4, comparado aos outros solos estudados (Figura 1). Neste solo, as mudas de leucena e de sabiá alcançaram 52,2 e $52,9 \mathrm{~cm}$, respectivamente, aos 76 e 62 dias após o transplantio, superando $(\mathrm{p}<0,01)$ o crescimento observado nos demais solos. No solo Agricultura 4, a palheteira alcançou $42,2 \mathrm{~cm}$ aos 70 dias do transplantio, crescimento comparável aos solos Agricultura 3 e de Mata 3 e 4, o que indica maior adaptação a condições de solo. Em todas as espécies, o menor comprimento do caule das plantas foi observado no solo de área Degradada 2, embora, nestas condições, as medidas de comprimento do caule não diferissem significativamente de alguns solos estudados.

O crescimento em diâmetro do colo das mudas das três espécies também foi favorecido no solo Agricultura 4 (Figura 2). Assim, neste solo, as mudas de leucena e palheteira, com 8 e 9,1 mm de diâmetro, respectivamente, superaram $(\mathrm{p}<0,01)$ os outros solos avaliados. Para a leguminosa sabiá, nos solos Agricultura 4 (leguminosa calopogônio) e Agricultura 6 (cana-de-açúcar), observaram-se os maiores diâmetros das mudas com valores médios de 5,9 e 4,3 mm, respectivamente.

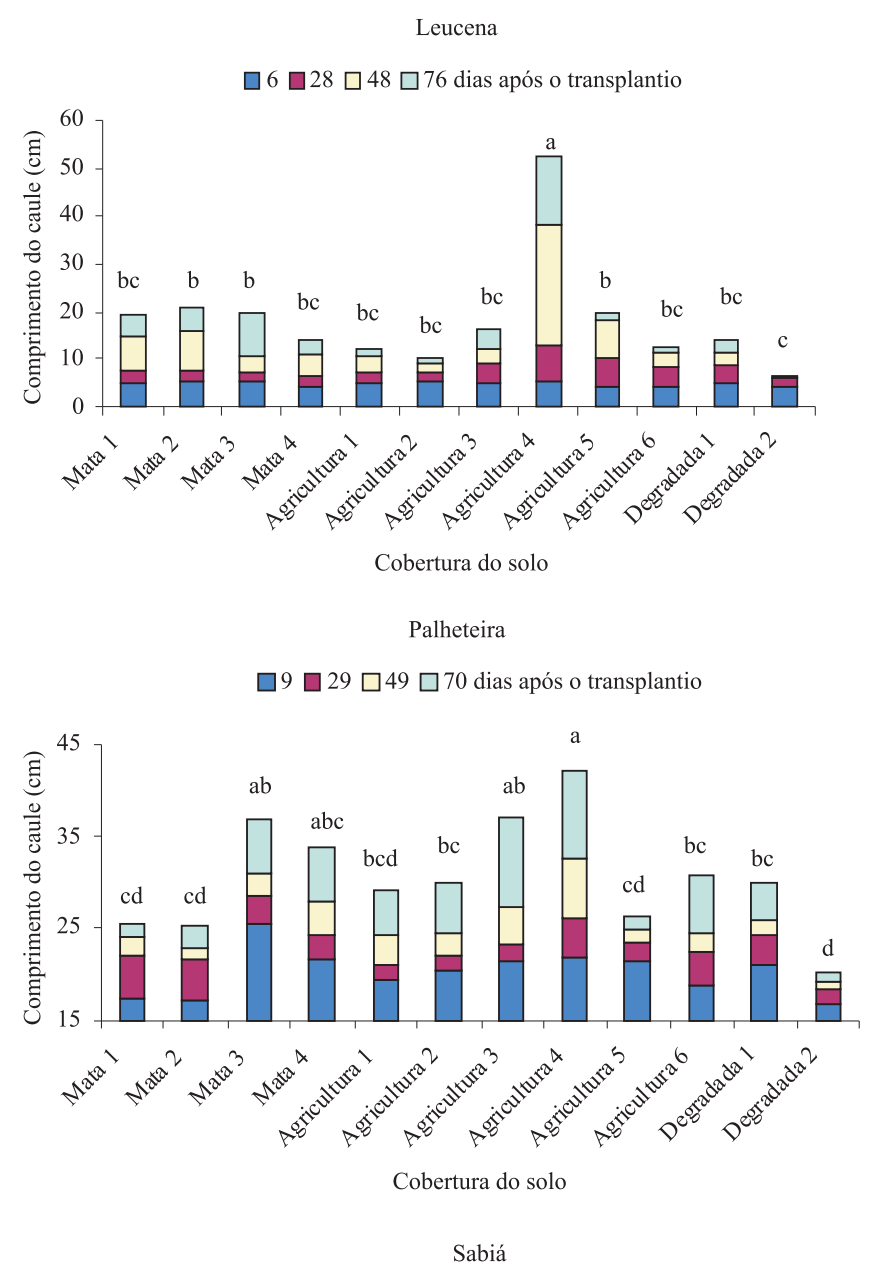

$\square 11 \square 29 \square 52 \square 62$ dias após o transplantio

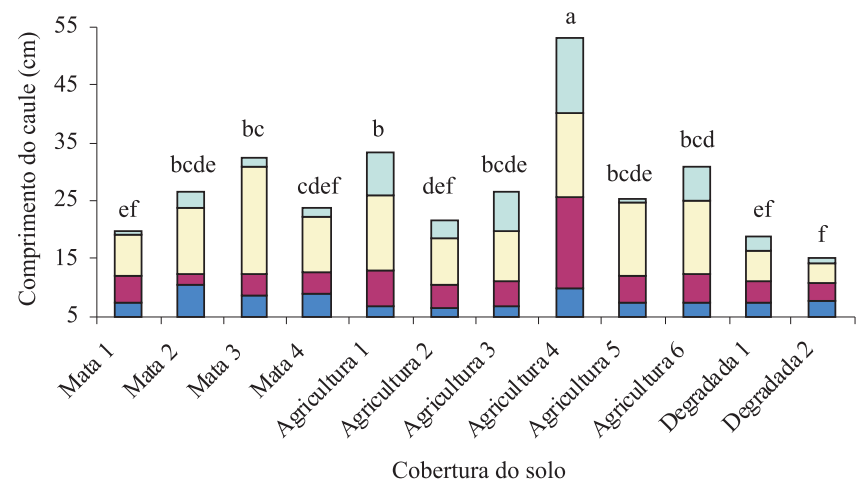

Figura 1. Aumentos médios no comprimento do caule de mudas de leucena, palheteira e sabiá, aos 76, 70 e 62 dias de transplantio, respectivamente, em solos coletados em áreas com diferentes formas de uso da terra, da Zona da Mata de Pernambuco. Os coeficientes de variação foram 24,55, 10,54 e $10,54 \%$ para leucena, palheteira e sabiá, respectivamente. Comparações feitas no último dia da avaliação de cada espécie. Médias com mesma letra não diferem entre si pelo teste $\mathrm{F}$ $(\mathrm{p}<0,01)$. 


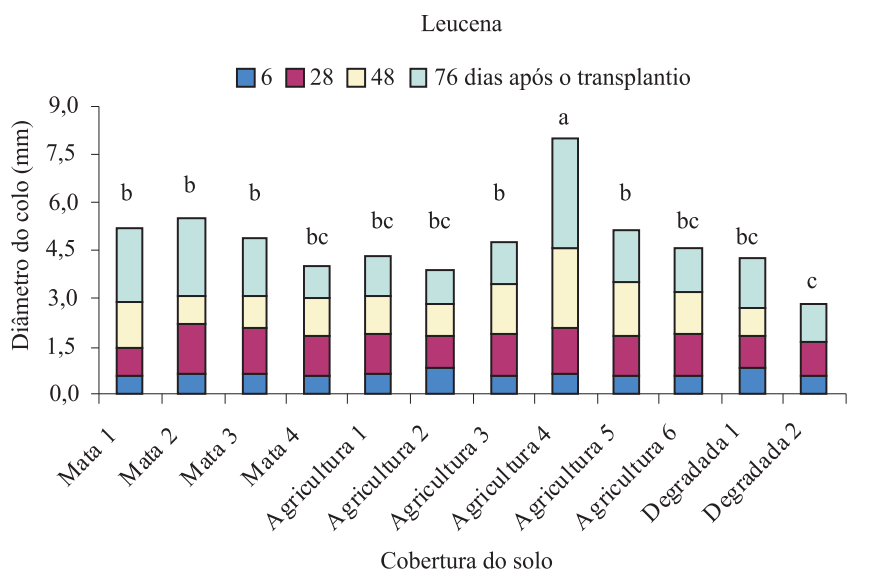

Palheteira

$\square 9 \square 29 \square 49 \square 70$ dias após o transplantio

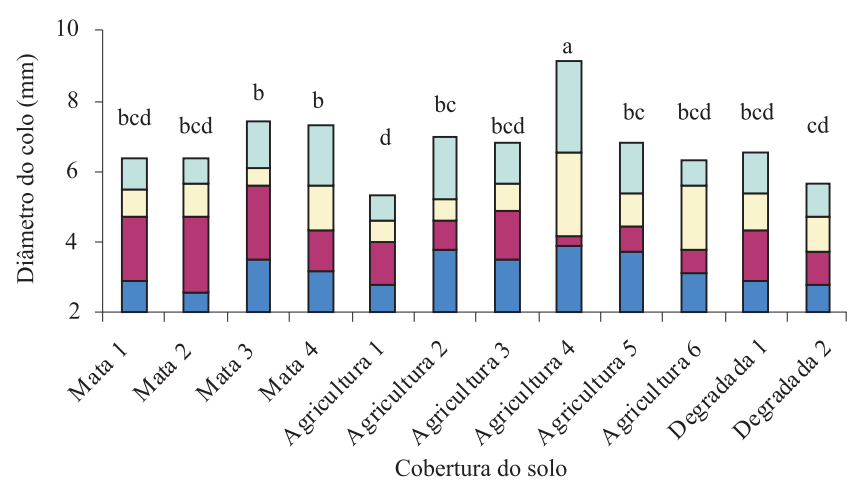

Sabiá

$\square 11 \quad \square 29 \quad \square 52 \quad \square 62$ dias após o transplantio

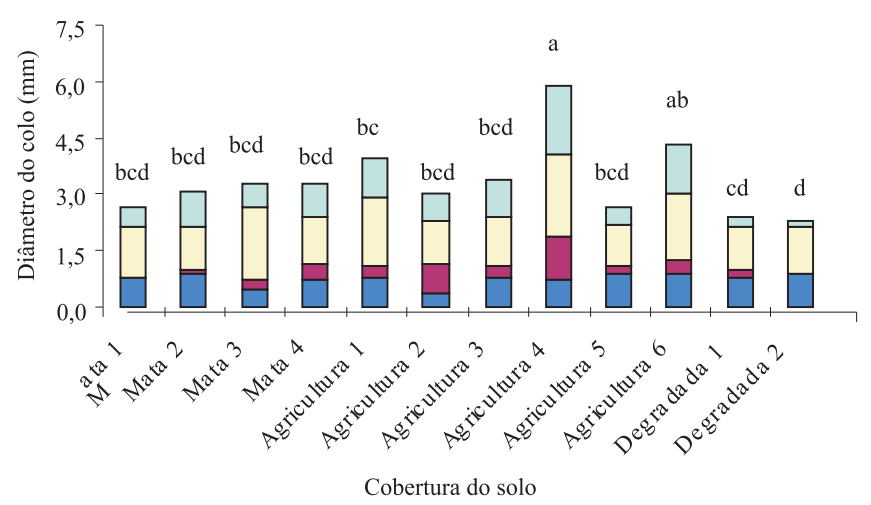

Figura 2. Aumentos médios no diâmetro do colo de mudas de leucena, palheteira e sabiá, aos 76, 70 e 62 dias de transplantio, respectivamente, em solos coletados em áreas de diferentes formas de uso da terra, da Zona da Mata de Pernambuco. Os coeficientes de variação foram 12,65, 7,58 e $17,07 \%$ para leucena, palheteira e sabiá, respectivamente. Comparações feitas no último dia da avaliação de cada espécie. Médias com mesma letra não diferem entre si pelo teste $\mathrm{F}$ $(\mathrm{p}<0,01)$.
No solo Agricultura 4, a cobertura proporcionada pelo calopogônio foi relacionada à boa fertilidade deste solo (Latossolo Vermelho-Amarelo) e, foram observados valores elevados de capacidade de troca catiônica (CTC), soma e saturação de bases, baixos níveis de alumínio, acidez moderada e teores medianos de fósforo (Tabelas 3 e 4).

A propriedade das leguminosas de melhorar as características químicas dos solos onde se desenvolvem foi demonstrada por Teklehaimanot \& Anim-Kwapong (1996) com Albizia zigia em solos da África. Do mesmo modo, foi observado que no solo Agricultura 4, as três espécies apresentaram maior biomassa na parte aérea e nas raízes e o desenvolvimento das plantas superou o verificado em outros solos (Tabela 5). Foi observado pouco desenvolvimento das plantas nos solos amostrados em áreas degradadas, especialmente quanto à biomassa seca da parte aérea da leguminosa sabiá. Nesta espécie, a biomassa da parte aérea em solo de Mata 3 (Espodossolo) superou os demais, o que evidencia seu potencial de adaptação a esta classe de solo. A palheteira apresentou as maiores médias de desenvolvimento da parte aérea e das raízes.

Entre as espécies estudadas, verificou-se menor desenvolvimento radicular da leucena o que evidencia maior dificuldade de estabelecimento dessa espécie nos solos amostrados (Tabela 5). Vale et al. (1996) verificaram que o desenvolvimento das raízes de leucena é sensível à acidez do solo e ao teor de alumínio, o que pode explicar o pouco desenvolvimento das raízes. Com elevada rusticidade e comportamento agressivo, a leucena é uma árvore cujo cultivo se expandiu na região tropical e é a de melhor desempenho dentro do gênero, que reúne 22 espécies, que crescem sob as mais variadas condições de clima e solo (Hughes, 1998).

Apesar da época de colheita diferenciada de cada espécie, a biomassa seca da parte aérea da palheteira apresentou aumento relativo no desenvolvimento de 53,2 e $38,5 \%$ maior que o de leucena e sabiá, respectivamente, o que evidencia boa capacidade de prosperar em diferentes solos, mesmo sem insumos. Para a produção relativa da biomassa seca da raiz, a palheteira foi 58,3 e 73,3\% maior que leucena e sabiá, respectivamente.

A leucena apresentou maior dificuldade de nodulação por estirpes de rizóbio nativas dos solos da Zona da Mata de Pernambuco, com média de 1 nódulo por vaso (Tabela 6), e ocorrência natural de rizóbios nas amostras somente em $22 \%$ das plantas analisadas, enquanto no 
sabiá, foi de $86 \%$ e, na palheteira, $100 \%$. Em seis dos solos coletados na Zona da Mata pernambucana, as mudas de leucena não nodularam e o baixo número de nódulos correspondeu também à baixa biomassa seca de nódulos, não ultrapassando $30 \mathrm{mg}$ vaso $^{-1}$. Bala et al. (2003) avaliaram a nodulação natural de leucena em solos de diferentes partes do mundo e a espécie formou nódulos em apenas 60\% deles. Sanginga et al. (1985) estudaram a nodulação da leucena em solo francoarenoso da Nigéria e também constataram população de rizóbios com baixa competitividade e $78 \%$ dos nódulos foram formados pela estirpe adicionada ao solo.

Essa baixa nodulação, em solos sem adição de rizóbio, foi explicada por Duhoux \& Dommergues (1985) pela alta especificidade hospedeira da leucena. Espécies com especificidade em relação aos rizóbios têm maiores respostas à inoculação de estirpes selecionadas que espécies promíscuas (pouco específicas). Leguminosas dos gêneros Parapiptadenia, Sesbania e Leucaena são específicas quanto ao grupo de inoculação e apresentam maior compatibilidade com estirpes de rizóbios isoladas do próprio hospedeiro (Friori et al., 1998). Porém, em outro trabalho foi observado que a leucena pode nodular com mais de um gênero de rizóbios e, no Brasil, são recomendadas estirpes de Bradyrhizobium elkanii e Rhizobium sp. para uso como inoculante comercial para esta espécie de planta (Menna et al., 2006).

Na palheteira, a média, entre os solos, de 155 nódulos por vaso (Tabela 6) é evidência de baixa especificidade hospedeira quanto à nodulação e corresponde a alta infectividade e desenvolvimento de biomassa nodular. A boa nodulação da palheteira nos solos incluiu solos coletados sob mata, solos agrícolas com mandioca (Agricultura 1 e 2) e com cobertura de leguminosas e mesmo solo procedente da área Degradada 1, que evidencia a compatibilidade desta espécie com os rizóbios nativos.

As mudas da espécie sabiá não nodularam quando cresceram no solo de Mata 4 (Tabela 6) e, nos solos de Agricultura 5 (com cana-de-açúcar) e Degradado 2, somente dois de cada três vasos apresentaram mudas noduladas. A melhor formação de nódulos nessa espécie ocorreu nos solos Agricultura 4 e 6, o que está de acordo com Jankovski (1989), que observou abundante nodulação do sabiá em solos do Ceará, Piauí e Rio

Tabela 5. Biomassa seca da parte aérea e da raiz de mudas de leucena, palheteira e sabiá, em solos coletados em áreas com diferentes formas de uso da terra, da Zona da Mata de Pernambuco, aos 76, 70 e 62 dias de transplantio, respectivamente, sem fertilização ${ }^{(1)}$.

\begin{tabular}{|c|c|c|c|c|c|c|}
\hline \multirow[t]{2}{*}{ Cobertura do solo } & \multicolumn{3}{|c|}{ Biomassa seca da parte aérea $\left(\mathrm{g}\right.$ vaso $\left.^{-1}\right)$} & \multicolumn{3}{|c|}{ Biomassa seca da raiz $\left(\right.$ g vaso $\left.^{-1}\right)$} \\
\hline & Leucena & Palheteira & Sabiá & Leucena & Palheteira & Sabiá \\
\hline Mata 1 & $2,94 \mathrm{bc}$ & $4,49 \mathrm{e}$ & 2,21de & $1,64 b c$ & $4,13 \mathrm{~cd}$ & $0,72 \mathrm{bcd}$ \\
\hline Mata 2 & $3,11 b c$ & 4,97de & 2,49de & $1,53 b c$ & $2,88 \mathrm{~cd}$ & $0,53 \mathrm{~cd}$ \\
\hline Mata 3 & $3,36 \mathrm{~b}$ & $9,17 \mathrm{~b}$ & $4,62 b c$ & $1,82 \mathrm{bc}$ & $6,99 \mathrm{ab}$ & $1,33 \mathrm{~b}$ \\
\hline Mata 4 & $1,96 \mathrm{bc}$ & $8,30 \mathrm{bc}$ & $2,45 \mathrm{de}$ & $1,39 b c$ & $3,57 \mathrm{~cd}$ & $1,13 \mathrm{bcd}$ \\
\hline Agricultura 1 & $1,86 \mathrm{bc}$ & 4,89de & $5,13 b$ & $1,30 \mathrm{bc}$ & $1,86 \mathrm{~d}$ & $1,31 b c$ \\
\hline Agricultura 2 & $1,48 \mathrm{bc}$ & $5,50 \mathrm{cde}$ & $2,40 \mathrm{de}$ & $1,07 b c$ & $3,67 \mathrm{~cd}$ & $0,88 \mathrm{bcd}$ \\
\hline Agricultura 3 & $2,45 \mathrm{bc}$ & $7,85 \mathrm{bcd}$ & $3,56 \mathrm{bcd}$ & $1,32 \mathrm{bc}$ & $2,80 \mathrm{~cd}$ & $0,90 \mathrm{bcd}$ \\
\hline Agricultura 4 & $12,68 \mathrm{a}$ & $15,25 \mathrm{a}$ & $14,61 \mathrm{a}$ & $5,42 \mathrm{a}$ & $9,17 \mathrm{a}$ & $2,90 \mathrm{a}$ \\
\hline Agricultura 5 & $3,22 \mathrm{bc}$ & $5,81 \mathrm{cde}$ & 3,03de & $2,40 \mathrm{~b}$ & $5,16 \mathrm{bc}$ & $1,04 \mathrm{bcd}$ \\
\hline Agricultura 6 & $1,87 \mathrm{bc}$ & $5,16 \mathrm{cde}$ & $5,63 b$ & $1,19 b c$ & $2,65 \mathrm{~cd}$ & $1,21 b c$ \\
\hline Degradada 1 & $1,78 \mathrm{bc}$ & $5,75 \mathrm{cde}$ & $1,69 \mathrm{e}$ & $0,96 b c$ & $3,59 \mathrm{~cd}$ & $0,60 \mathrm{bcd}$ \\
\hline Degradada 2 & $0,63 \mathrm{c}$ & $2,62 \mathrm{e}$ & $1,14 \mathrm{e}$ & $0,26 \mathrm{c}$ & $2,15 \mathrm{~d}$ & $0,41 d$ \\
\hline Média dos solos & 3,11 & 6,65 & 4,09 * & 1,69 & 4,05 & 1,08 \\
\hline Teste de F & $36,79^{* *}$ & $26,92^{* *}$ & $85,89^{* *}$ & $10,57^{* *}$ & $14,67^{* *}$ & $17,26^{* *}$ \\
\hline CV (\%) & 28,64 & 16,31 & 16,39 & 40,38 & 23,79 & 25,02 \\
\hline
\end{tabular}

${ }^{(1)}$ Médias seguidas da mesma letra, na coluna, não diferem entre si pelo teste de Tukey $(\mathrm{p}<0,01)$. 
Grande do Norte, onde essa espécie predomina em solos arenosos e profundos. As mudas de sabiá que se desenvolveram nos solos sob Agricultura 1, 2, 3, 4 e 6, apresentaram biomassa nodular seca destacável comparada aos solos sob mata ou degradados. A inoculação de rizóbios em sabiá em solos de Pernambuco foi pesquisada por Stamford \& Silva (2000), que estudaram o efeito da calagem e da inoculação em mudas em Argissolo Vermelho-Amarelo, textura argilo- arenosa, coletado em Goiana, Município da Zona da Mata de Pernambuco, em que comprovaram a presença de rizóbios nativos compatíveis com a eficiência das estirpes inoculadas, NFB 539, NFB 577 e NFB 578.

As determinações efetuadas para o nitrogênio foliar e total das leguminosas arbóreas estudadas encontramse na Tabela 7. Nas folhas, na média dos solos, a maior concentração de $\mathrm{N}$ foliar foi verificada em palheteira. Quanto a leucena, que teve nodulação irregular, as

Tabela 6. Nodulação (número e biomassa seca dos nódulos) em mudas de leucena, palheteira e sabiá, em solos coletados em áreas com diferentes formas de uso da terra, na Zona da Mata de Pernambuco, aos 76, 70 e 62 dias de transplantio, respectivamente, sem fertilização ${ }^{(1)}$.

\begin{tabular}{|c|c|c|c|c|c|c|}
\hline \multirow[t]{2}{*}{ Cobertura do solo } & \multicolumn{3}{|c|}{ Número de nódulos } & \multicolumn{3}{|c|}{ Biomassa seca dos nódulos $\left(\right.$ g vaso $\left.^{-1}\right)$} \\
\hline & Leucena & Palheteira & Sabiá & Leucena & Palheteira & Sabiá \\
\hline Mata 1 & $4 \mathrm{a}$ & $79 b c$ & $20 \mathrm{bcd}$ & $0,03 \mathrm{a}$ & $0,11 d$ & $0,06 \mathrm{cde}$ \\
\hline Mata 2 & $0 \mathrm{a}$ & $176 \mathrm{ab}$ & 5 cde & $0,00 \mathrm{a}$ & $0,19 \mathrm{~cd}$ & $0,04 \mathrm{cde}$ \\
\hline Mata 3 & $0 \mathrm{a}$ & $189 \mathrm{ab}$ & 4 cde & $0,00 \mathrm{a}$ & $0,42 \mathrm{abc}$ & $0,07 \mathrm{cde}$ \\
\hline Mata 4 & $6 a$ & $276 a$ & $0 \mathrm{e}$ & $0,03 \mathrm{a}$ & $0,33 \mathrm{abcd}$ & $0,00 \mathrm{e}$ \\
\hline Agricultura 1 & $0 \mathrm{a}$ & $186 \mathrm{ab}$ & $22 \mathrm{bc}$ & $0,00 \mathrm{a}$ & $0,31 \mathrm{abcd}$ & $0,28 \mathrm{ab}$ \\
\hline Agricultura 2 & $0 \mathrm{a}$ & $135 \mathrm{ab}$ & $20 \mathrm{bc}$ & $0,00 \mathrm{a}$ & $0,36 \mathrm{abcd}$ & $0,18 \mathrm{abc}$ \\
\hline Agricultura 4 & $2 \mathrm{a}$ & $269 \mathrm{a}$ & $96 a$ & $0,01 \mathrm{a}$ & $0,56 a$ & $0,16 \mathrm{abcd}$ \\
\hline Agricultura 5 & $0 \mathrm{a}$ & $25 c$ & $2 \mathrm{de}$ & $0,00 \mathrm{a}$ & $0,13 \mathrm{~cd}$ & 0,09 bcde \\
\hline Agricultura 6 & $1 \mathrm{a}$ & $58 \mathrm{bc}$ & $48 \mathrm{ab}$ & $0,01 \mathrm{a}$ & $0,31 \mathrm{abcd}$ & $0,34 \mathrm{a}$ \\
\hline Degradada 1 & $1 \mathrm{a}$ & $164 \mathrm{ab}$ & $4 \mathrm{cde}$ & $0,03 \mathrm{a}$ & 0,25 bcd & 0,09 bcde \\
\hline Degradada 2 & $0 \mathrm{a}$ & $9 \mathrm{c}$ & $4 \mathrm{cde}$ & $0,00 \mathrm{a}$ & $0,07 \mathrm{~d}$ & $0,02 \mathrm{de}$ \\
\hline Média dos solos & 1 & 155 & 22 & 0,01 & 0,30 & 0,13 \\
\hline Teste F & $1,25^{\mathrm{ns}}$ & $13,24^{* *}$ & $19,36^{* *}$ & $0,99^{\text {ns }}$ & $6,96^{* *}$ & $8,30^{* *}$ \\
\hline
\end{tabular}

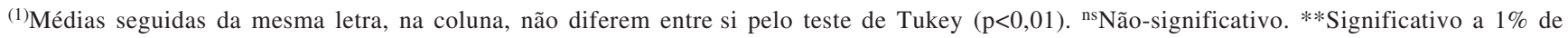
probabilidade.

Tabela 7. Teor de $\mathrm{N}$ foliar e $\mathrm{N}$ total acumulado na parte aérea de mudas de leucena, palheteira e sabiá, em solos coletados em áreas com diferentes formas de uso da terra, na Zona da Mata de Pernambuco, aos 76, 70 e 62 dias de transplantio, respectivamente, sem fertilização ${ }^{(1)}$.

\begin{tabular}{|c|c|c|c|c|c|c|}
\hline \multirow[t]{2}{*}{ Cobertura do solo } & \multicolumn{3}{|c|}{ Teor de nitrogênio foliar $(\mathrm{g} \mathrm{kg})$} & \multicolumn{3}{|c|}{$\mathrm{N}$ total acumulado na parte aérea $\left(\mathrm{mg} \mathrm{vaso}^{-1}\right)$} \\
\hline & Leucena & Palheteira & Sabiá & Leucena & Palheteira & Sabiá \\
\hline Mata 1 & $23,6 \mathrm{ab}$ & $29,3 \mathrm{bc}$ & $25,9 \mathrm{a}$ & $69,60 \mathrm{~b}$ & $132,39 \mathrm{de}$ & $56,74 \mathrm{de}$ \\
\hline Mata 2 & $25,0 \mathrm{ab}$ & $28,4 \mathrm{bc}$ & $19,6 \mathrm{a}$ & $69,23 \mathrm{~b}$ & $141,10 \mathrm{de}$ & $56,27 \mathrm{de}$ \\
\hline Mata 3 & $16,1 b$ & $33,5 \mathrm{ab}$ & $22,9 a$ & $51,57 \mathrm{bc}$ & $306,34 b c$ & $105,29 \mathrm{bcd}$ \\
\hline Mata 4 & $30,8 \mathrm{a}$ & $34,7 \mathrm{ab}$ & $29,2 \mathrm{a}$ & $49,92 \mathrm{bc}$ & $288,16 b c$ & $71,37 \mathrm{cde}$ \\
\hline Agricultura 1 & $18,0 \mathrm{ab}$ & $37,8 \mathrm{ab}$ & $28,9 \mathrm{a}$ & $32,94 \mathrm{bc}$ & $179,18 \mathrm{cde}$ & $148,87 \mathrm{bc}$ \\
\hline Agricultura 2 & $18,8 \mathrm{ab}$ & $39,2 \mathrm{ab}$ & $28,5 \mathrm{a}$ & $27,83 \mathrm{bc}$ & $218,37 \mathrm{bcd}$ & $68,17 \mathrm{de}$ \\
\hline Agricultura 3 & $21,6 a b$ & $41,3 \mathrm{a}$ & $21,9 a$ & $54,12 \mathrm{bc}$ & $323,03 b$ & 84,45 bcde \\
\hline Agricultura 4 & $21,0 \mathrm{ab}$ & $34,5 \mathrm{ab}$ & $30,0 \mathrm{a}$ & $265,13 a$ & $525,98 \mathrm{a}$ & $435,76 a$ \\
\hline Agricultura 5 & $20,0 \mathrm{ab}$ & $16,6 \mathrm{~d}$ & $21,7 \mathrm{a}$ & $64,37 b c$ & $95,41 \mathrm{de}$ & $65,87 \mathrm{de}$ \\
\hline Agricultura 6 & $22,2 \mathrm{ab}$ & $32,3 \mathrm{abc}$ & $26,7 \mathrm{a}$ & $41,49 \mathrm{bc}$ & $174,95 \mathrm{cde}$ & $152,00 \mathrm{~b}$ \\
\hline Degradada 1 & $20,3 \mathrm{ab}$ & $34,2 \mathrm{ab}$ & $19,0 \mathrm{a}$ & $36,95 \mathrm{bc}$ & $196,88 \mathrm{bcd}$ & $33,10 \mathrm{de}$ \\
\hline Degradada 2 & $19,0 \mathrm{ab}$ & $22,5 \mathrm{~cd}$ & $21,3 \mathrm{a}$ & $11,97 \mathrm{c}$ & $59,70 \mathrm{e}$ & $24,72 \mathrm{e}$ \\
\hline Média dos solos & 21,4 & 32,0 & 24,6 & 64,60 & 220,12 & 108,55 \\
\hline Teste F & $2,41^{*}$ & $12,70^{* *}$ & $1,23^{\mathrm{ns}}$ & $35,84^{* *}$ & $23,72^{* *}$ & $52,01^{* *}$ \\
\hline CV (\%) & 9,50 & 5,82 & 12,62 & 29,33 & 20,42 & 24,43 \\
\hline
\end{tabular}


mudas no solo de Mata 4 tiveram concentrações de $\mathrm{N}$ foliar superior $(30 \%)$ às do solo de Mata $3(\mathrm{p}<0,05)$ (Tabela 7). $\mathrm{O}$ valor de $\mathrm{N}$ total acumulado nas mudas de leucena no solo Agricultura 4, favorecidas pelo maior desenvolvimento da biomassa da parte aérea, foi superior aos demais solos estudados.

Em palheteira em condições naturais, sem fertilização ou adição de rizóbios, a concentração de $\mathrm{N}$ foliar de $4,13 \%$ em solo sob Agricultura 3 (cobertura da leguminosa feijão-macassar) foi superior $(\mathrm{p}<0,01)$ à das mudas desenvolvidas nos solos de Mata 1 e 2, Agricultura 5 e Degradado 2 (Tabela 7). Para esta espécie, na parte aérea das mudas que se desenvolveram nos solos de Mata 3 e 4 nos solos Agricultura 1, 2, 6 e de área Degradada 1, o $\mathrm{N}$ foliar apresentou valores acima da média dos solos $(3,20 \%)$. O maior acúmulo de $\mathrm{N}$ total na palheteira foi observado no solo Agricultura 4 (Tabela 7), que superou os demais solos. Entretanto, houve diferença significativa para o $\mathrm{N}$ total acumulado na parte aérea da palheteira em solos de mata e, nos solos de Mata 3 e 4, o suprimento de $\mathrm{N}$ para as folhas foi maior $(\mathrm{p}<0,01)$ que nos de Mata 1 e 2.

Quanto a leguminosa sabiá, a concentração de $\mathrm{N}$ foliar na parte aérea não diferiu entre os solos avaliados e a média foi de $2,46 \%$. É possível que, nessa espécie, a seleção de estirpes de rizóbios eficientes e adaptadas a solos locais contribua para um incremento na absorção de $\mathrm{N}$ pela via simbiótica. Para a determinação do $\mathrm{N}$ total na parte aérea da espécie sabiá, as diferenças entre solos foram significativas e as mudas no solo Agricultura 4 apresentaram valores superiores $(\mathrm{p}<0,01)$ aos verificados em outros solos.

A espécie de leguminosa sabiá é nativa do Nordeste, e no Ceará, há cultivos intensivos para produção de estacas, varas e lenha, ocupando 30 mil hectares (Leal Júnior et al., 1999). Os benefícios da dupla inoculação de rizóbios e micorrizas na espécie sabiá foram demonstrados, identificando-se o FMA Acaulospora longuta como eficiente para a espécie em solos com diferentes texturas (Mergulhão et al., 2001). Mesmo sem adição de rizóbio, a leguminosa sabiá tem aptidão para recuperação de solos e, em Planossolo, Andrade et al. (2000) observaram que o acúmulo anual de serapilheira de $10,1 \mathrm{t} \mathrm{ha}^{-1}$ de biomassa, em plantios de sete anos, proporciona adições ao solo de $185 \mathrm{~kg} \mathrm{ha}^{-1}$ de $\mathrm{N} \mathrm{e}$ $6,8 \mathrm{~kg} \mathrm{ha}^{-1}$ de P.

Ao se considerar as variáveis de crescimento, biomassa, nodulação e distribuição do $\mathrm{N}$ total analisadas para leucena, palheteira e sabiá, é possível classificar o potencial ecológico das espécies para a fixação de $\mathrm{N}_{2} \mathrm{e}$ a eficiência da nodulação natural nos solos do litoral Pernambucano. A palheteira apresenta o maior potencial, seguida por sabiá e leucena.

A biomassa seca dos nódulos e o $\mathrm{N}$ total na parte aérea das espécies apresentaram correlação significativa para a palheteira (Figura 3), o que permite concluir sobre a eficiência do processo da nodulação e fixação de $\mathrm{N}_{2}$ com populações nativas de rizóbios nos solos estudados.

Foi também verificado que a relação entre nodulação e $\mathrm{N}$ total em leucena e sabiá não foi significativa. Campêlo \& Campêlo (1970) identificaram um mesmo grupo de inoculação cruzada para leucena e sabiá (ambas da tribo Eumimoseae) e, na ausência de outros fatores que afetam a relação simbiótica, o fato de ambas não encontrarem populações nativas de rizóbios compatíveis nos solos estudados é indicação de baixa presença e competitividade de rizóbios deste grupo de inoculação.

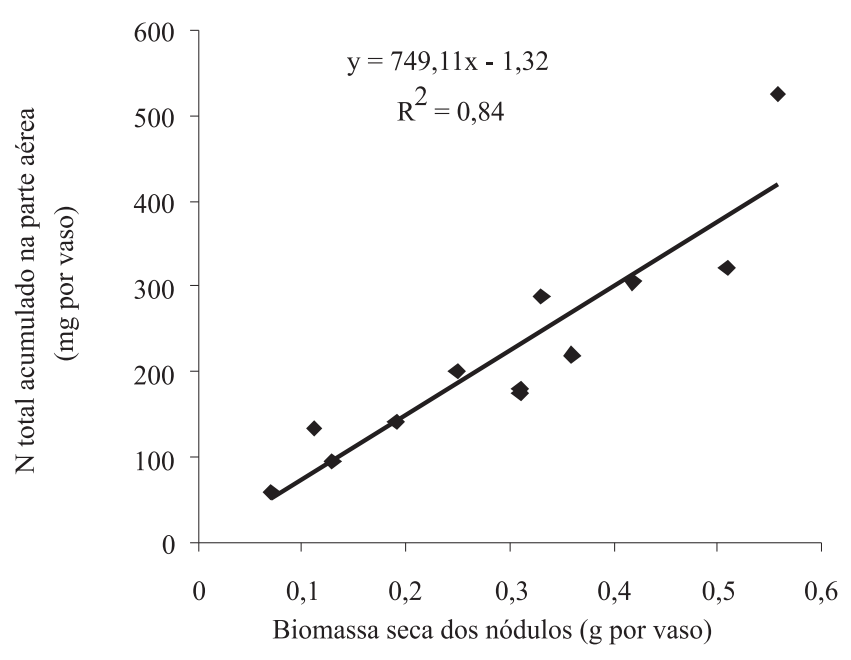

Figura 3. Regressão linear da biomassa seca dos nódulos e $\mathrm{N}$ total acumulado na parte aérea de mudas de palheteira, em solos coletados em áreas com diferentes formas de uso da terra, na Zona da Mata de Pernambuco, aos 70 dias de transplantio, sem fertilização $(\mathrm{p}<0,01)$. 


\section{Conclusões}

1. A frequiência de populações nativas de rizóbios compatíveis com leucena é baixa, comparado às compatíveis com palheteira e sabiá.

2. A palheteira apresenta nodulação natural abundante, eficiência na fixação de $\mathrm{N}_{2}$ e compatibilidade com as populações de rizóbios nativas do solo.

3. O crescimento, desenvolvimento, nodulação e acúmulo de nitrogênio de leucena, palheteira e sabiá, na fase de mudas, são favorecidos em solo agricultável com cobertura da leguminosa Calopogonium mucunoides.

4. Palheteira concentra o maior potencial para fixação de $\mathrm{N}_{2}$ e eficiência da nodulação com populações nativas de rizóbios de solos da Zona da Mata de Pernambuco, seguida por sabiá e leucena.

\section{Referências}

ANDRADE, A.G.; COSTA, G.S.; FARIA, S.M. Deposição e decomposição da serapilheira em povoamentos de Mimosa caesalpiniifolia, Acacia mangium e Acacia holosericea com quatro anos de idade em Planossolo. Revista Brasileira de Ciência do Solo, v.24, p.777-785, 2000.

ARAÚJO, E.L.; TABARELLI, M. Estudo de ecologia de populações de plantas do nordeste do Brasil. In: ARAÚJO, E.L.; MOURA, A.N.; SAMPAIO, E.V.S.B.; GESTINARI, L.M.S.; CARNEIRO, J.M.T. (Ed.). Biodiversidade, conservação e uso sustentável da flora do Brasil. Recife: UFRPE, SBB, Seção Regional Pernambuco, Imprensa Universitária, 2002. p.135-142.

BALA, A.; MURPHY, P.J.; OSUNDE, A.O.; GILLER, K.E. Nodulation of tree legumes and the ecology of their native rhizobial populations in tropical soils. Applied Soil Ecology, v.22, p.211223, 2003.

BARBOSA, M.R.V.; THOMAS, W.W. Biodiversidade, conservação e uso sustentável da Mata Atlântica no Nordeste. In: ARAÚJO, E. de L.; MOURA, A. do N.; SAMPAIO, E. de S.B.; GESTINARI, L.M. de S.; CARNEIRO, J. de M.T. (Ed.). Biodiversidade, conservação e uso sustentável da flora do Brasil. Recife: UFRPE/ SBB, Imprensa Universitária, 2002. p.19-22.

BEZERRA NETO, E.; BARRETO, L.P. Métodos de análises químicas em plantas. Recife: Imprensa Universitária da UFRPE, 2004. 165p.

BURGOS, N.; SANTOS, J.C.P.; ARAÚJO FILHO, J.C.; CAVALCANTI, A.C. Solos: caracterização e ocorrência. In: CAVALCANTI, J.A.C. Recomendações de adubação para o estado de Pernambuco: $2^{\underline{a}}$ aproximação. 2.ed. Recife: Empresa Pernambucana de Pesquisa Agropecuária, 1998. p.3-28.

CAMPÊLO, A.B.; CAMPÊLO, C.R. Eficiência da inoculação cruzada entre espécies da subfamília Mimosoideae. Pesquisa Agropecuária Brasileira, v.5, p.333-337, 1970.
DUHOUX, E.; DOMMERGUES, Y. The use of nitrogen fixing trees in forest and soil restoration in the tropics. In: SSALI, H.; KEYA, S.O. (Ed.). Biological nitrogen fixation in Africa. Nairobi: Mircen, 1985. p.384-400.

EMBRAPA. Centro Nacional de Pesquisa de Solos (Rio de Janeiro, RJ). Manual de métodos de análise de solo. 2.ed. Rio de Janeiro, 1997. 212p.

EMBRAPA. Centro Nacional de Pesquisa de Solos (Rio de Janeiro, RJ). Sistema brasileiro de classificação de solos. Rio de Janeiro, 1999. 412p.

FORTES, J.L.O.; BALIEIRO, F.C.; FRANCO, A.A. Leguminosas arbóreas como agentes de recuperação de áreas degradadas. In: MOURA, E.G. (Coord.). Agroambientes de transição entre o trópico úmido e o semi-árido do Brasil: atributos; alterações; uso na produção familiar. 1.ed. São Luiz: Uema, 2004. p.101-132.

FRANCO, A.A.; FARIA, S.M. The contribution of $\mathrm{N}_{2}$ fixing tree legumes to land reclamation and sustentability in the tropics. Soil Biology and Biochemistry, v.29, p.897-903, 1997.

FRIORI, L.; MALATÉS, D.; IRIGOYEN, I.; DODERA, R. Promiscuity for nodulation and effectivity in the $\mathrm{N}_{2}$-fixing legume tree Acacia caven in Uruguay. Applied Soil Ecology, v.7, p.239244, 1998.

HUGHES, C.E. Leucaena: manual de recursos genéticos. Oxford: University of Oxford, Department of Plant Sciences, 1998. 280p. (Tropical forestry papers, 37).

JANKOVSKI, T. Mimosa caesalpiniaefolia, espécie de interesse agrossilvicultural. Informativo Agroflorestal, v.1, p.13, 1989.

LEAL JÚNIOR, G.; SILVA, J.A.; CAMPELLO, R.C.B. Proposta de manejo florestal sustentado do sabiá (Mimosa caesalpiniaefolia Benth.). Crato: Ibama, 1999.15p. (Boletim técnico, $3)$.

LEMOS, R.C.; SANTOS, R.D. Manual de descrição e coleta de solo no campo. 2.ed. Campinas: Sociedade Brasileira de Ciência do Solo, 1996. 84p.

MENNA, P.; HUNGRIA, M.; BARCELLOS, F.G.; BANGEL, E.V.; HESS, P.N.; MARTÍNEZ-ROMERO, E. Molecular phylogeny base on the 16S rRNA gene of elite rhizobial strains used in Brazilian commercial inoculants. Systematic and Applied Microbiology, v.29, p.315-332, 2006.

MERGULHÃO, A.C.E.S.; SILVA, M.L.R.B.; BURITY, H.A.; STAMFORD, N.P. Influência da dupla inoculação rizóbio e fungos micorrizas-arbusculares em plantas de sabiá sob solos de diferentes texturas. Ecossistema, v.26, p.42-47, 2001.

SANGINGA, N.; MULONGOY, K.; AYANABA, A. Effect of inoculation and mineral nutrients on nodulation and growth of Leucaena leucocephala. In: SSALI, H.; KEYA, S.O. (Ed.). Biological nitrogen fixation in Africa. Nairobi: Mircen, 1985. p.419-427.

STAMFORD, N.P.; SILVA, R.A. Efeito da calagem e inoculação de sabiá em solo da mata úmida e do semi-árido de Pernambuco. Pesquisa Agropecuária Brasileira, v.35, p.1037-1045, 2000.

TEKLEHAIMANOT, Z.; ANIM-KWAPONG, G. The potentials of Albizia zygia (DC.) Macbride for soil amelioration. Applied Soil Ecology, v.3, p.59-68, 1996. 
VALE, F.R.; FURTINI NETO, A.E.; RENÓ, N.B.; FERNANDES, L.A.; RESENDE, A.V. Crescimento radicular de espécies florestais em solo ácido. Pesquisa Agropecuária Brasileira, v.31, p.609-616, 1996.

VANDAME, P.; GORIS, J.; CHEN, W.-M.; VOS, P.; WILLENS, A. Burkholderia tuberum sp. nov. and Burkholderia phymatum sp. nov., nodulate of roots of tropical legumes. Systematic and Applied Microbiology, v.25, p.507-512, 2002.
VIANNA, V.M.; TABANEZ, A.J.; BATISTA, J.L. Dynamics and restoration of forest fragments in the Brazilian Atlantic moist forest. In: LAURANCE, W.F.; BIERREGAARD JÚNIOR, R.O. (Ed.). Tropical forest remnants: ecology management, and conservation of fragmented communities. Chicago: The University of Chicago Press, 1997. p.351-365.

ZAHRAN, H.H. Rhizobia from wild legumes: diversity, taxonomy, ecology, nitrogen fixation and biotechnology. Journal of Biotechnology, v.91, p.143-153, 2001.

$\overline{\text { Recebido em } 2 \text { de maio de } 2006 \text { e aprovado em } 31 \text { de outubro de } 2006}$ 